\title{
Two Conceptions of Subjective Experience ${ }^{1}$
}

\author{
Justin Sytsma and Edouard Machery
}

\begin{abstract}
Do philosophers and ordinary people conceive of subjective experience in the same way? In this article, we argue that they do not and that the philosophical concept of phenomenal consciousness does not coincide with the folk conception. We first offer experimental support for the hypothesis that philosophers and ordinary people conceive of subjective experience in markedly different ways. We then explore experimentally the folk conception, proposing that for the folk, subjective experience is closely linked to valence. We conclude by considering the implications of our findings for a central issue in the philosophy of mind, the hard problem of consciousness.
\end{abstract}

Our first goal in this article is to examine whether ordinary people (viz. people without training in philosophy or in consciousness studies) and philosophers conceive of subjective experience in a similar way. Philosophers see subjective experiences as including such diverse mental states as seeing red and feeling pain, treating them as having something in common, namely that they are phenomenal—viz. that they share the second-order property that there is "something it is like" (Nagel 1974) to be in these mental states. We provide suggestive evidence that the folk, by contrast, do not conceive of subjective experience in this way. Our second goal is to explore this folk conception for its own sake. We successively consider two accounts. We first examine whether the folk treat perceptual states differently from bodily sensations or felt emotions, taking the latter, but not the former, to be subjectively experienced. This might be phrased in terms of the folk distinguishing between those states that tell us about the world

\footnotetext{
${ }^{1}$ The first author did most of the work on this article. We would like to thank Dave Chalmers, David Danks, Tony Jack, Joshua Knobe, Jonathan Livengood, Shaun Nichols, Peter Pagin, and Philip Robbins for their comments on previous versions of this article. We also would like to thank Eric Schwitzgebel for his reply to a talk based on this article at annual meeting of the Society for Philosophy and Psychology in 2008. Thanks also to the audiences in Santa Cruz, Stockholm, Lund, and Gothenburg.
} 
outside our skin (the products of the external senses) and those states that tell us about ourselves from the skin in (the products of the internal senses). Rejecting this first account, we argue for an alternative hypothesis: For the folk, subjective experience is tightly linked to valence. ${ }^{2}$ As a result, people distinguish between states that essentially have a valence (such as feeling pain or anger), those that do not have a valence (such as seeing red), and those that have a valence as well as a prominent perceptual component (such as smelling banana).

While the folk conception of subjective experience is fascinating in its own right, it is also of substantial philosophical importance. Our third goal in this article is to investigate the philosophical implications of the divergence between ordinary people’s and philosophers' conceptions of subjective experience. We argue, first, that our findings cast doubt on the claim that the philosophical concept of phenomenal consciousness is shared by the folk or is a part of folk psychology. Second, if our analysis of the folk conception is correct, then it raises serious doubt about whether there is a hard problem of consciousness to be solved. The hard problem is typically justified on the grounds that phenomenal consciousness is "the most central and manifest aspect of our mental lives” (Chalmers 1995, 207). Our findings challenge this justification: If the folk do not recognize that states such as seeing red and feeling pain are phenomenal, then it is hardly credible that phenomenal consciousness is central and manifest. This does not necessarily mean that there is no hard problem of consciousness, but it does call on philosophers to provide a better justification for the reality of this problem.

\footnotetext{
${ }^{2}$ Throughout we will use the term "valence" as follows: mental states have a valence if and only if they have a hedonic value for the subject. That is, mental states have a valence if and only if they are pleasurable (they then have a positive valence) or disagreeable (they then have a negative valence). Not all mental states have a valence, and valenced states are more or less pleasurable or disagreeable. Typically, but perhaps not necessarily, disagreeable mental states motivate people to act as to discontinue these, while pleasurable mental states motivate people to act so as to perpetuate them.
} 
We begin in Section 1 by briefly characterizing the philosophical conception of subjective experience. In Section 2, we discuss the shortcomings of recent work in psychology, philosophy, and experimental philosophy that investigates folk intuitions related to consciousness. We conclude that this work is poorly designed to investigate whether philosophers and ordinary people conceive of subjective experience similarly. In Sections 3, 4, and 5, we aim to rectify this situation by examining people's judgments about perceptual experiences, bodily sensations, and felt emotions. In Section 6, we examine the philosophical implications of our findings about the folk conception of subjective experience.

\section{The Philosophical Conception of Subjective Experience}

For most contemporary philosophers, subjective experience is characterized by its phenomenality. There is, of course, much disagreement in the literature about what phenomenal consciousness is. Still, according to one standard line (and the one we will be interested in), mental states such as seeing red, feeling pain, hearing a C\#, feeling anger, etc., all share the second-order property that it is like something to be in these states. What it is like to be in pain is distinct from what it is like to see red, but for both states, there is something it is like to be in them. "Phenomenal consciousness" refers to this second-order property. As Ned Block puts it (1995, 227): "Phenomenal consciousness is experience; what makes a state phenomenally conscious is that there is something 'it is like' (Nagel 1974) to be in that state.” Similarly, John Searle (1994, xi) holds that it is one of the "simple and obvious truths about the mind" that "[w]e all have inner subjective qualitative states of consciousness.” Finally, Chalmers writes eloquently (1995, 201):

The really hard problem of consciousness is the problem of experience. When we think and perceive, there is a whir of information-processing, but there is also a subjective 
aspect.... This subjective aspect is experience. When we see, for example, we experience visual sensations: the felt quality of redness, the experience of dark and light, the quality of depth in a visual field. Other experiences go with perception in different modalities: the sound of a clarinet, the smell of mothballs. Then there are bodily sensations... mental images... the felt quality of emotion.... What unites all of these states is that there is something it is like to be in them. All of them are states of experience. (10; emphasis added)

Phenomenally conscious mental states are typically divided into a number of types in the philosophical literature. The most common type is perceptual experiences such as seeing, hearing, or smelling, followed closely by bodily sensations such as pain and hunger (Levin 1998). Felt emotions such as fear, rage, joy and felt moods such as elation, depression, boredom are typically added to this list (Tye 2003). ${ }^{3}$ These four types of phenomenal states (perceptual experiences, bodily sensations, felt emotions, and felt moods) are typically contrasted with nonphenomenal intentional states like belief and desire.

Perceptual experiences of colors and bodily sensations of pains are easily the most frequently discussed in the philosophical and scientific literature. For example, Francis Crick describes qualia (the phenomenal properties of mental states) in terms of "the redness of red or the painfulness of pain” (1995, 9fn). This strategy is typical - the concepts of phenomenal consciousness and qualia are generally drawn out through examples; as David Papineau puts it, “the idea is best introduced by examples rather than definitions” (2002, 13; see also Block 1995). And the first examples are typically colors and pains; as Janet Levin opens her Routledge Encyclopedia of Philosophy entry on “Qualia”:

The term... [is] most commonly understood to mean the qualitative, phenomenal or 'felt' properties of our mental states, such as the throbbing pain of my current headache, or the peculiar blue of the afterimage I am experiencing now. Though it seems undeniable that

\footnotetext{
${ }^{3}$ While we follow convention in referring to mental states like seeing red and smelling banana as perceptual experiences, it is worth noting that some hold that mental states here classified as bodily sensations, felt emotions, or felt moods are also perceptual (e.g., Prinz 2006). We wish to thank an anonymous referee for Philosophical Studies for pointing this out.
} 
at least some of our mental states have qualia, their existence raises a number of philosophical problems. (§0)

Given the illustrative centrality of perceptual experiences and bodily sensations to articulating the concept of phenomenal consciousness, if the folk and philosophers conceive similarly of subjective experience, we should expect them to treat perceptual experiences and bodily sensations analogously in these regards. In particular, we should expect the folk to deny that an entity, be it a simple organism, a simple robot, or a zombie, is not phenomenally conscious, that lacks phenomenal consciousness can see red just as readily as they deny that it can be in pain. Daniel Dennett conforms with this expectation, for example, when he states that the robot $\operatorname{Cog}^{4}$ "cannot yet see or hear or feel at all” $(1996,16)$.

\section{Previous Research related to the Folk's Conception of Subjective Experience}

In this second section, we critically discuss three main lines of experimental research related to the folk conception of subjective experience. While this work is intriguing in its own right, we argue that none of the studies is adequate for determining whether the philosophical concept of phenomenal consciousness really coincides with what Block $(2004,785)$ has called the “common-sense conception of subjective experience.”

\subsection{Experience and Agency}

Heather Gray, Kurt Gray, and Daniel Wegner’s fascinating study on “Dimensions of Mind Perception” (2007) reports empirical findings that people tend to distinguish between two broad aspects of having a mind. Gray et al. label these dimensions Experience (including hunger, fear, pain, pleasure, rage) and Agency (including self-control, morality, memory, emotion

\footnotetext{
${ }^{4}$ See http://www.ai.mit.edu/projects/humanoid-robotics-group/cog/cog.html.
} 
recognition). They had participants compare a host of characters (e.g., God, a 7-week-old fetus, the robot Kismet ${ }^{5}$, a frog, a corpse) on a range of mental capacities. For instance, participants were asked "whether a girl of 5 is more or less likely to feel pain than is a chimpanzee" (619). They found a clear divide between experiential capacities and agentive capacities. The possessions of mental capacities like hunger, fear, pain (etc.) were correlated with each other, as were the possessions of mental capacities like self-control, morality, memory (etc.), while the possessions of mental capacities across these two groupings were poorly correlated. Thus, while a human baby scored low on Agency, but high on Experience, the robot Kismet scored very low on Experience, but had a moderate Agency score.

These findings are no doubt very interesting, but they fail to show that the philosophical concept of phenomenal consciousness coincides with the common-sense conception of subjective experience, in spite of what the term “Experience”-Gray et al.'s name of their second dimension of mind perception—might suggest. ${ }^{6}$ As we have seen in Section 1, for philosophers, phenomenality is a second-order property shared by such diverse states as perceptual experiences, bodily sensations, and felt emotions. Perceptual states like seeing red are in fact the typical illustrative example of phenomenally conscious mental states. By contrast, the states Gray et al. tested (e.g., pain, pleasure, rage, etc.) were all non-perceptual. As a result, it remains unclear whether the folk think that mental states such as seeing red, feeling pain, and feeling rage have in common that they are phenomenally conscious, as they should if they conceive of subjective experience in the same way as philosophers.

\footnotetext{
${ }^{5}$ See http://www.ai.mit.edu/projects/sociable.

${ }^{6}$ Heather Gray explicitly equated her Experience dimension with phenomenal consciousness at the 2007 Association for the Scientific Study of Consciousness conference.
} 


\subsection{Minds and Objects}

In contrast to Piaget's (1929) claim that "children are adualistic rather than dualistic in that they fail to segregate two realms: the psychical and the physical, the subjective and the objective, the mental and the real” (Wellman and Estes 1986, 910), psychologist Paul Bloom has argued that “even very young babies treat people differently from objects” $(2004,14)$. He holds that we have an "evolved capacity to understand and respond to the minds of other people" and "we also have the evolved capacity to perceive and reason about material objects” (5). Bloom concludes that from an early age on, people are intuitive dualists in the sense that they naturally distinguish entities with minds from mere objects. Among other things, this corresponds with the fact that "empathy comes early and easily" (114); from an early age people tend to empathize with some entities (those with minds), but not others.

Philosopher Philip Robbins and cognitive neuroscientist Tony Jack (2006) have drawn on Bloom's work to argue that a further stance, rooted in our evolved "capacity for empathy and moral understanding” (74), should be added to Dennett's (1987) distinction between the intentional and physical stances: "The phenomenal stance corresponds to a component of social cognition that, like folk physics, is relatively independent of mindreading—namely, moral cognition" (61; italics added). Moral cognition is then implicated in generating our "intuitive dualism" and specifically identified as "generating intuitions about the non-physical nature of consciousness” (61).

Robbins and Jack's approach to the folk conception of subjective experience suffers from the same problem as Gray et al.'s. They hold that "regarding something as a locus of experience is a kind of emotional sensitivity" (70). Thus they note that "it is usually pleasant to observe another's pleasure, and distressing to observe their distress" and state that "the capacity for such 
responses... is essential to the phenomenal stance" (70). The problem is that not all phenomenal states are associated with pleasure or distress (think, e.g., about seeing a red patch). Robbins and Jack might be correct that "phenomenal states typically have some hedonic value for the bearer, either positive (e.g. pleasure, joy) or negative (e.g. pain, sadness)" (70; italics added), but this is just to underline that the distinction between mental states that are associated with pleasure or distress is distinct from the philosophical distinction between phenomenal and non-phenomenal mental states.

\subsection{Group Agents and Individuals}

How the folk understand subjective experience has been investigated most specifically by Joshua Knobe and Jesse Prinz (2008). In their second of five studies, Knobe and Prinz asked people to evaluate how natural it is to ascribe a range of mental states to a group agent (Acme Corporation). They found that people seem to be unwilling to ascribe phenomenally conscious mental states (such as feeling depressed) to the corporation, while being disposed to ascribe mental states that are not phenomenally conscious, such as propositional attitudes, to it. In addition, in their fourth study, Knobe and Prinz provided some suggestive evidence that while people are willing to ascribe a mental state such as being upset or regretting to a group agent, they are reluctant to ascribe a mental state such as feeling upset or feeling regret to it. Knobe and Prinz interpret this body of evidence as showing that (i) the folk distinguish between

phenomenally conscious mental states and mental states that are not phenomenally conscious and (ii) that in contrast to the latter mental states, the ascription of phenomenally conscious mental states does not depend merely on the functional properties of the ascribee's states. 
In contrast to Gray et al.’s and Robbins and Jack’s approaches, Knobe and Prinz’s study seems to support the contention that philosophers' concept of phenomenal consciousness coincides with the common-sense conception of subjective experience (see also Huebner et al. forthcoming). Indeed, they conclude that "ordinary people-people who have never studied philosophy or cognitive science-actually have a concept of phenomenal consciousness” (68).

Unfortunately, there are a few problems with Knobe and Prinz’s study (Arico

forthcoming; Sytsma and Machery 2009). Particularly, as we have argued elsewhere (Sytsma and Machery 2009), there is a confound inherent in this approach: Corporations differ in some significant behavioral and functional ways from individuals. A group agent like Acme Corporation is distributed; it does not have an individual body, although it is comprised of such bodies. As such, Acme cannot smile in happiness or grimace in disgust. It is thus difficult to determine whether people deny that Acme can experience great joy, feel excruciating pain, or vividly imagine a purple square because they believe that a group agent like Acme cannot have a phenomenal state or because they believe that a group agent like Acme does not have the proper functional organization for having mental states like joy and pain. For these reasons, we find that Knobe and Prinz's study of the ascription of mental states to corporations is inconclusive about the folk conception of subjective experience.

\section{Study 1: Seeing Red and Feeling Pain}

Previous research is by and large uninformative about whether philosophers’ concept of phenomenal consciousness coincides with the common-sense conception of subjective experience. In this section, we provide and discuss some new evidence that the folk and philosophers conceive of subjective experience in markedly different ways. 
The rationale behind our first study is straightforward. If the philosophical concept of phenomenal consciousness coincides with the folk's conception of subjective experience, we would expect their judgments about robots like Cog to be in line with Dennett's (Section 1): They would treat perception analogously to bodily sensations, tending to deny both to a simple robot. The Mental State Intuitions Study was designed to test this prediction. In the first experiment, participants were given a description of a relatively simple, non-humanoid robot performing tasks expected to elicit ascriptions of either a perceptual experience (seeing red) or a bodily sensation (feeling pain) in humans. Given the role of visual experiences and bodily sensations such as pain in spelling out the philosophical concept of phenomenal consciousness, we hypothesized that philosophers' attribution of the perceptual experience would not dissociate from their attribution of the bodily sensation. If the folk conceive of subjective experience in the same way as philosophers, they should give a similar pattern of answers.

671 participants completed surveys through the Mental State Intuitions Study website. ${ }^{7,8}$ Participants were divided into two groups based on their responses to biographical questions concerning their philosophical training. ${ }^{9}$ They randomly received one of four scenarios describing an agent manipulating a red object. The scenarios were varied along two dimensions. In half of the scenarios, the agent was a simple robot (Jimmy), while in the other half, the agent was a normal human male (Timmy). Moreover, in half of the scenarios, the manipulation was successful and participants were asked whether the agent (either the robot or the human) "saw red" on a 7-point scale anchored at 1 with "clearly no," at 4 with "not sure," and at 7 with

\footnotetext{
${ }^{7}$ http://www.JustinSytsma.com/MSIS

${ }^{8}$ See appendix for demographical information and data analysis for each experiment.

9 "Philosophers" were defined as participants who indicated at least some graduate training in philosophy or either had already completed or were in the process of completing an undergraduate degree with a major in philosophy. Note that the results do not change when we count as philosophers only the participants who have some graduate training in philosophy.
} 
“clearly yes.” In the other half, the agent was electrically shocked and participants were asked whether the agent "felt pain" on the same 7-point scale. In each pair of vignettes the agents are described in behaviorally identical ways; in the first pair, the agents' behavior involves discrimination between colors, while in the second, the behavior is typical of a pain-response. ${ }^{10}$ The two robot scenarios read as follows ${ }^{11}$ :

Jimmy (shown below) is a relatively simple robot built at a state university. He has a

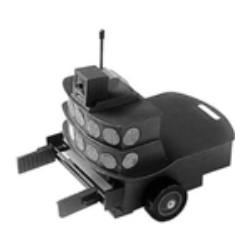
video camera for eyes, wheels for moving about, and two grasping arms with touch sensors that he can move objects with. As part of a psychological experiment, he was put in a room that was empty except for one blue box, one red box, and one green box (the boxes were identical in all respects except color). An instruction was then transmitted to Jimmy. It read: "Put the red box in front of the door." Jimmy did this with no noticeable difficulty. Did Jimmy see red?

Jimmy (shown below ${ }^{12}$ ) is a relatively simple robot built at a state university. He has a video camera for eyes, wheels for moving about, and two grasping arms with touch sensors that he can move objects with. As part of a psychological experiment, he was put in a room that was empty except for one blue box, one red box, and one green box (the boxes were identical in all respects except color). An instruction was then transmitted to Jimmy. It read: "Put the red box in front of the door." When Jimmy grasped the red box, however, it gave him a strong electric shock. He let go of the box and moved away from it. He did not try to move the box again. Did Jimmy feel pain when he was shocked?

Participants were randomly ascribed to one of the four scenarios. After the participants read the scenario they were asked the target question ("Did Timmy/Jimmy see red?" or "Did Timmy/Jimmy feel pain?”), as well as a variation concerning other people: Participants were asked whether ordinary people would say that the agent (either the robot or the human) saw red

\footnotetext{
${ }^{10}$ We emphasize that the robot and the undergraduate behave in the same way. Thus, if participants were to ascribe differently pain and seeing red to the robot and the undergraduate, this difference could not plausibly be explained by reference to the functional and behavioral properties of the two agents; rather, it would result from participants focusing on the phenomenal properties of these states. This stands in contrast with Knobe and Prinz's (2008) comparison of an individual agent and of a corporation.

${ }^{11}$ The complete set of probes is available at: HTTP://www.JustinSytsma.com/MSIS/probes.html

${ }^{12}$ The same image was used with each robot scenario in studies 1, 2, and 3; an image of a typical undergraduate was used in each of the human scenarios.
} 
or felt pain on the same 7-point scale. The questions were counterbalanced for order. Participants were then asked to explain their answers and to fill out a short biographical survey.

\subsection{Results}

Figure 1 and Table 1 summarize our results.

\begin{tabular}{c|cc|cc}
\hline \multirow{4}{*}{ Human } & \multicolumn{2}{|c}{ Seeing Red } & \multicolumn{2}{c}{ Feeling Pain } \\
\hline & Folk & Philosophers & Folk & Philosophers \\
\cline { 2 - 5 } & $N=55,5.98$ & $N=92,5.90$ & $N=62,6.15$ & $N=84,6.44$ \\
& $(1.25)^{* * *}$ & $(1.46)^{* * *}$ & $(1.01)^{* * *}$ & $(.87)^{* * *}$ \\
Robot & $N=52,5.15$ & $N=96,3.48$ & $N=59,2.54$ & $N=100,2.02$ \\
$(1.85)^{* * *}$ & $(1.94)^{* *}$ & $(1.99)^{* * *}$ & $(1.53)^{* * *}$ \\
\hline
\end{tabular}

$* p<.05 ; * * p<.01 ; * * * p<.005$

Table 1: Results of Study 1 (number of participants per condition, mean answer, and standard deviation in parentheses; significance tests compare means to the neutral answer, 4).

Consistent with our hypothesis, philosophers treated similarly feeling pain and seeing red. They

were unwilling to ascribe either the perceptual experience of seeing red or the bodily sensation of

feeling pain to the robot (the mean answers are significantly lower than 4). By contrast,

philosophers were willing to ascribe both states to a normal human male (the mean answers are

significantly higher than 4). Contrary to the hypothesis that the folk and philosophers conceive of

subjective experience similarly, however, ordinary people distinguished the perceptual state of

seeing red from the bodily sensation of feeling pain. They were willing to attribute the perceptual

experience to a simple robot that can effectively manipulate objects, but were not willing to

attribute feeling pain to this robot. In addition, the folk’s modal answer for feeling pain was 1

(like philosophers), while their modal answer for seeing red was 7 (unlike philosophers). By 
contrast, ordinary people did not differ from philosophers in their willingness to ascribe the perceptual state and the bodily sensation to a normal human male.

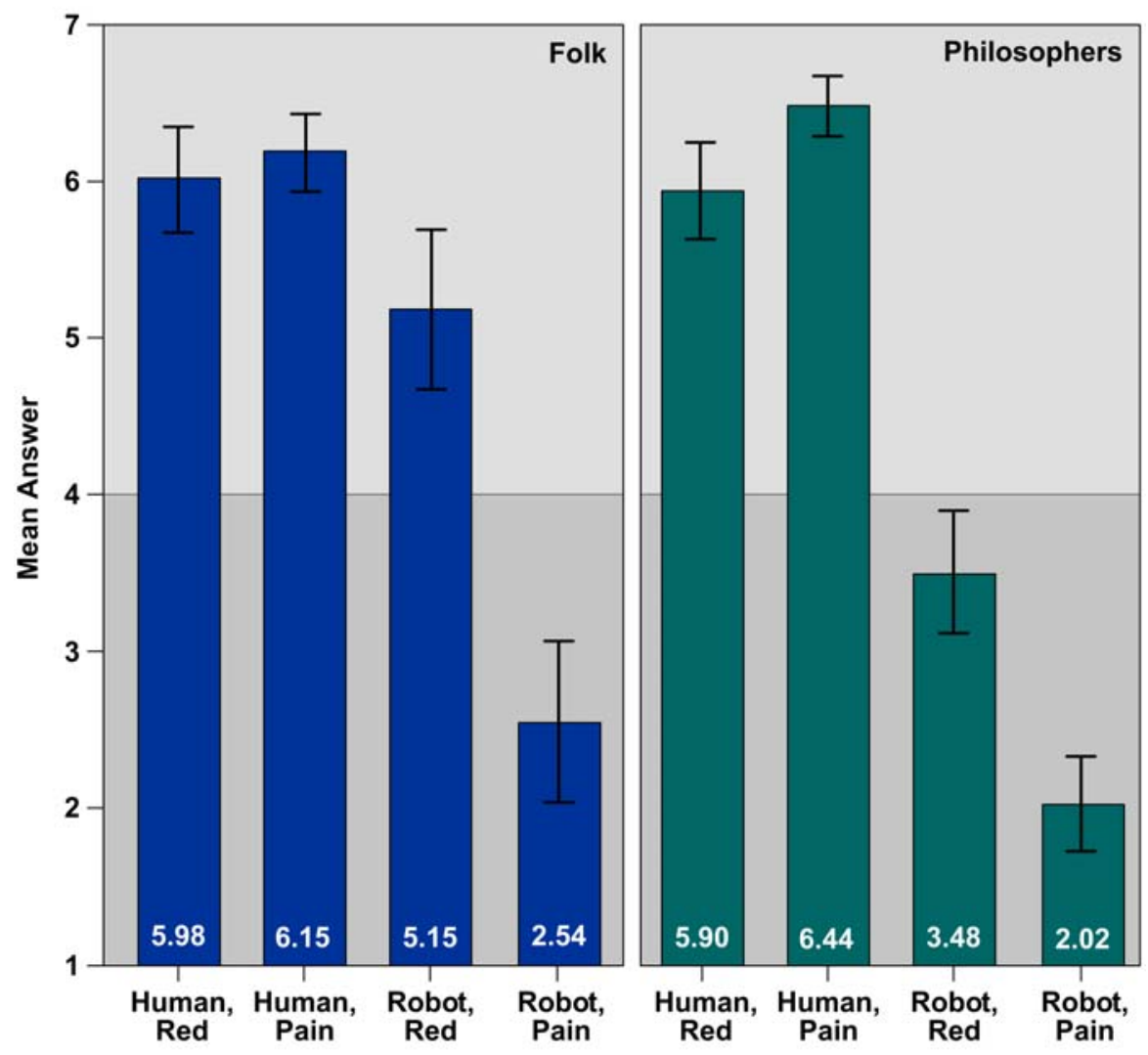

Figure 1: Results, Study 1 (error bars: 95\% confidence interval).

\subsection{Discussion}

In contrast to the prediction derived from the hypothesis that the philosophical concept of phenomenal consciousness coincides with the common-sense conception of subjective experience, the results show a clear divergence between philosophers and the folk: On average, the folk (but not philosophers) are willing to ascribe the perceptual state of seeing red to a simple robot. Given the illustrative centrality of the example of the redness of red to the philosophical concept of phenomenal consciousness, our results indicate that philosophers' concept of phenomenal consciousness is not how the folk understand subjective experience. 
In addition, it is worth noting that philosophers are not aware that their conception of subjective experience differs from the folk conception. Remember that in addition to asking participants whether they thought that Jimmy was in pain and was seeing red, we also asked them how ordinary people would answer these same questions. Philosophers' answers are wellcalibrated for Timmy’s pain, Timmy’s perception of red, and Jimmy’s pain. By contrast, for the robot's perception of red, philosophers' prediction about the ordinary people's answers is offthe-mark: They expected ordinary people to give only a neutral answer $(M=4.18 ; S D=1.81)$, while ordinary people’s mean answer was above 5 (Figure 2).
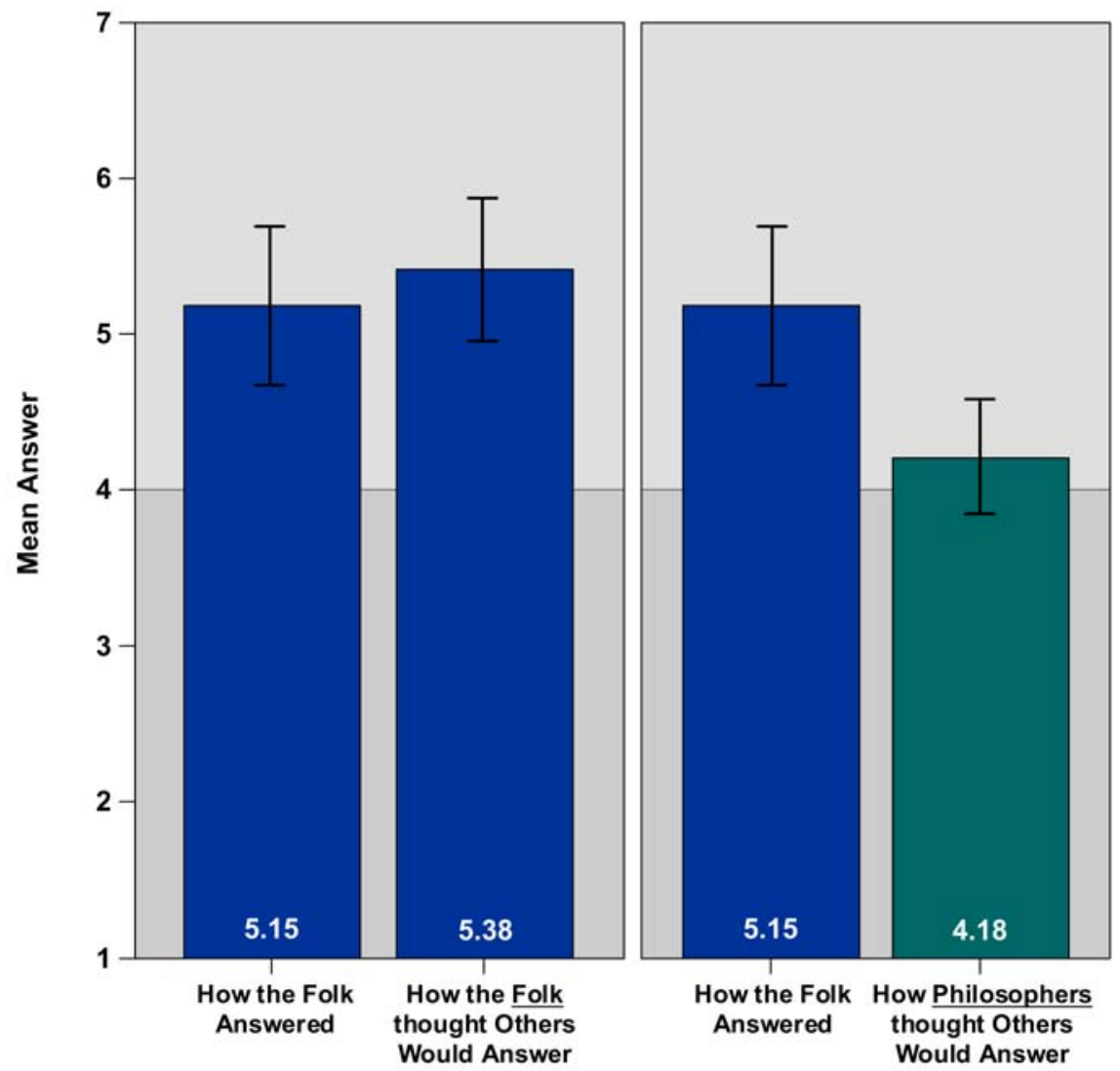

Figure 2: Comparison of the folk's mean answer for the question "Did Jimmy see red?”, with how the folk and philosophers thought ordinary people would answer (error bars: 95\% confidence interval). 
Philosophers' expectation about ordinary people's evaluation of the robot's perception of red follows their usual pattern for estimating ordinary people’s answer. Philosophers expected ordinary people to give approximately the same answer as themselves, but to be a bit less skeptical (by giving a somewhat higher answer). In contrast to philosophers, non-philosophers' evaluation of whether ordinary people will ascribe seeing red to the robot is well calibrated. They expected ordinary people to give a mean answer of 5.38, while ordinary people's mean answer was 5.15.

\subsection{Objections}

We now turn to two possible replies to the claim that philosophers and ordinary people conceive of subjective experience differently. Our critic assumes that the folk understand subjective experience similarly to philosophers. She must then explain the folk’s divergence from philosophers for the case of Jimmy seeing red in another way. The most obvious ways to do this are to argue that the folk understand the question "Did Jimmy see red?” differently than philosophers, or that the folk have divergent beliefs about Jimmy. We will consider each response in turn. ${ }^{13}$

First, it could be argued that "seeing red" is ambiguous. ${ }^{14}$ On one reading (which our critic might call "informational”), a creature sees red if its behavior is responsive to the distinction between red things and non-red things or, to put the same point somewhat differently,

\footnotetext{
${ }^{13}$ We briefly mention a third possible reply (Tony Jack, personal communication). A critic could argue that our hypothesis predicts that if we ask ordinary people whether Jimmy experience red, they would answer affirmatively. If they would answer negatively (as our critic suggests they would), then we would have to conclude that the folk conceive of subjective experience as philosophers do. In reply, we note that "experience" is a technical term and does not have the same meaning in ordinary English and in philosophy. In ordinary English, an experience typically is a significant interaction with an object (e.g., one might say "My encounter with the bear in the woods was a frightening experience"). For this reason, it is dubious that asking ordinary English speakers about a robot's experience would be of much relevance to study how they understand subjective experience.

${ }^{14}$ See, e.g., Huebner (forthcoming) for a related objection.
} 
if it can pick some information about red things from its environment and act on the basis of this information. In this sense, Jimmy certainly sees red (he performs the discrimination task). On a second reading (which our critic might call "phenomenal"), a creature sees red only if it has the appropriate phenomenal experience. In this sense, Jimmy does not see red, or so our critic maintains. The critic can then argue that in contrast to "seeing red," there is no informational reading of "feeling pain": one is in pain only if one has the appropriate phenomenal experience.

From this, our critic might argue that "seeing red" has the informational and the phenomenal readings both for the folk and for philosophers. However, the folk tend to understand "seeing red" according to its informational reading, while philosophers tend to understand it according to its phenomenal reading, which explains their divergent answers. Because "feeling pain" has only a phenomenal reading, philosophers and the folk give similar answers. If this proposal were correct, experiment 1 would not show that the folk understand phenomenal consciousness differently than philosophers, because for the folk as for philosophers, "seeing red” would still have a phenomenal reading. The folk would just interpret the question "Did Jimmy see red?" according to the informational reading of "seeing red," while philosophers would interpret it according to its phenomenal reading.

It should be noted that if the objection is to avoid being blatantly ad hoc, the critic owes us an explanation for the folk's divergence from philosophers in choosing the informational reading over the phenomenal reading of "seeing red." Regardless, the data simply do not bear out our critic's proposal. If she were right, we would expect that a reasonable proportion of the folk would answer negatively to the question “Did Jimmy see red?”—as philosophers do—while the remainder would answer positively. This is not the case, however. Figure 3 presents the 
distribution of answers for the folk: Almost all non-philosophers (84.6\%) gave an answer equal or superior to 4 .

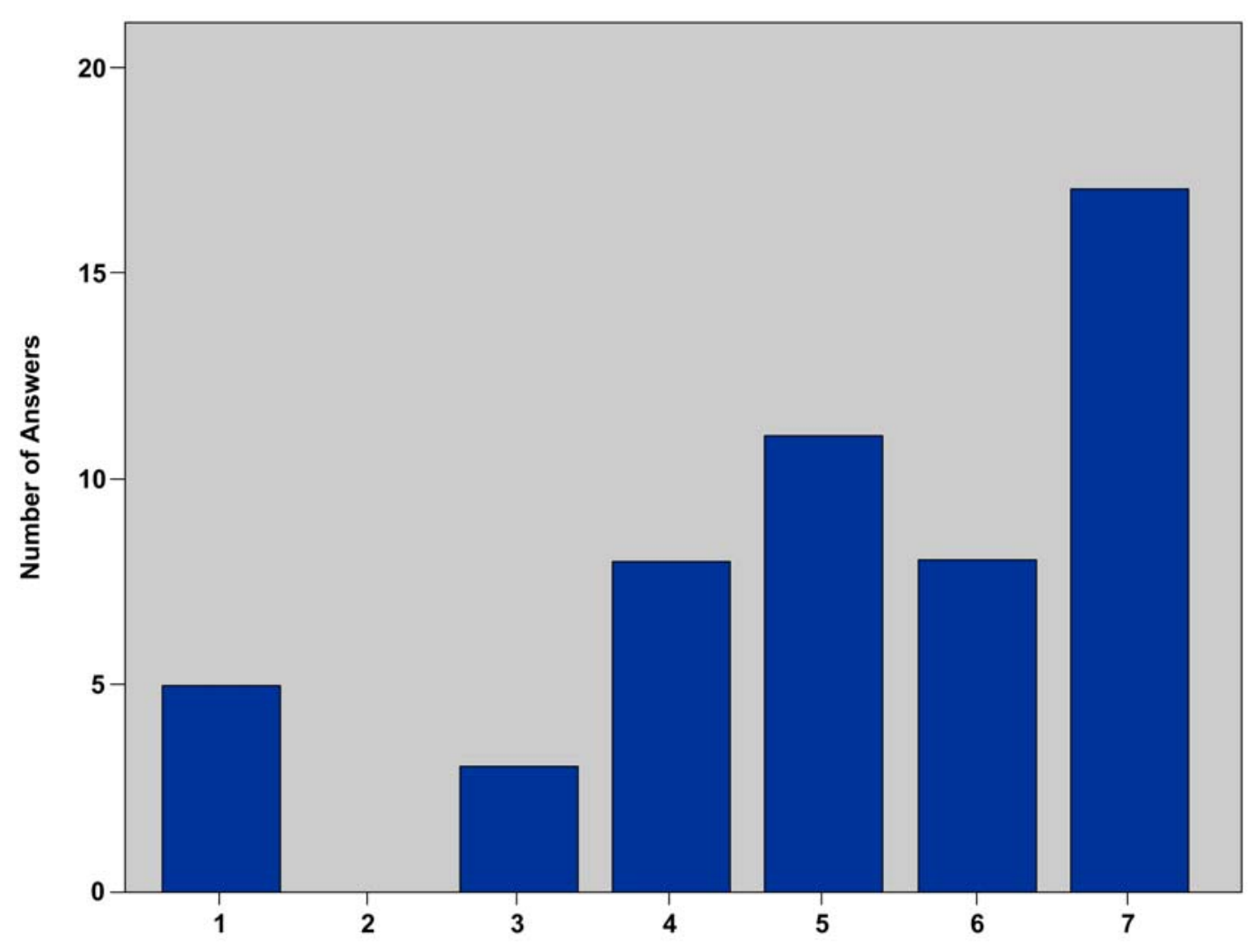

Figure 3: Distribution of the folk's answers for the question, "Did Jimmy see red?"

This first objection is further undermined by the explanations that participants gave for their answers. Philosophers tended to refer to phenomenal consciousness (or to qualia, secondary properties, etc.) in explaining their denial that the robot saw red. A few typical philosophical explanations of an answer of 1 (“clearly no"-philosophers' modal answer) to the question ("Did Jimmy see red?”), read as follows: “To actually see red requires experiencing the sensation of redness (qualia)"; "color is a secondary property”; "seeing red implies consciousness, not just ability to identify red"; "seeing is perceiving, and perceiving is conscious." In contrast, the three explanations given by non-philosophers who answered 1 to the question do not suggest a 
phenomenal reading; if anything they indicate a different analysis of "seeing"—an anthropocentric reading that restricts the term to humans and animals (see Bennett and Hacker 2003, for a related conceptual analysis of the term): “I’m not sure how color is understood by robots and computers"; "seeing is a human attribute"; "seeing is something which animals do."

Second, a critic could offer an alternative explanation of our results. Consider the following analogy. John and Joe might have the same concepts of right and wrong (say, both are utilitarian), but they might nonetheless disagree about whether the death penalty is wrong. They might disagree about the wrongness of the death penalty because they have different beliefs about the death penalty (for example, about its efficiency as a deterrent). Similarly, the disagreement between the folk and philosophers might not indicate that they conceive of subjective experience differently; rather, it might reflect that they have different beliefs about the robot Jimmy.

We have argued that if the philosophical concept of phenomenal consciousness coincides with the folk's conception of subjective experience, then we would expect them to treat seeing red and feeling pain analogously in denying both to a simple robot. The critic challenges this: Perhaps the folk do understand these states in the phenomenal sense, but unlike philosophers they believe that Jimmy is capable of having phenomenal visual experiences. Our argument assumes that the robot Jimmy (as described and pictured) is simple enough that if someone has the concept of phenomenal consciousness, then she will not feel that it applies to Jimmy. The critic denies this, arguing (in effect) that the folk are more lenient than philosophers in ascribing phenomenal consciousness. Besides an argument for supposing the folk to be lenient in this way, on the assumption that the folk really take Jimmy to be phenomenally conscious, the critic now 
owes us an explanation of why they deny that he feels pain. One possibility is that the folk tend to assume that Jimmy’s visual system is more complex than his touch system.

While we feel that these are indeed possibilities (that could be explored through further experimental work), none of them strikes us as especially likely. As noted above, the explanations that the folk offered for their responses do not suggest a phenomenal understanding of “seeing red.” Further, the details of the story do not support the assumption that Jimmy's visual system is significantly more complex than his touch system. Finally, while post-hoc explanations of our data that are compatible with the assumption that the folk's understanding of subjective experience coincides with philosophers' can be given, our positive account of the folk’s understanding of subjective experience suggests that this assumption is mistaken. We present this positive account in the following two sections.

\section{Study 2: Smelling Banana and Feeling Anger}

In study 1 , the folk deny that the robot Jimmy feels pain, but not that he sees red. What does this indicate about the folk understanding of subjective experience? One proposal that is suggested by the philosophical literature is that the folk’s understanding of subjective experience is based on a distinction between the internal senses and the external senses: being subjective and being internal would be identified according to this proposal. As Natika Newton put it, colors and pains "seem to lie at opposite extremes of internality and externality" $(1989,571)$. Thus, the folk might treat seeing red differently from feeling pain because the former is a product of an external sense while the latter is a product of an internal sense. If this explanation is correct, then we would expect the folk to be willing to ascribe other perceptual experiences (external) to Jimmy, but not felt emotions (internal). 
To test the internal/external hypothesis, participants were given variations on the scenarios from the first experiment. If the hypothesis is correct, the folk should be willing to ascribe the perceptual experience of odor to the robot Jimmy in the same way they were willing to ascribe the perceptual experience of red to him in study 1, while being reluctant to ascribe the felt emotion of anger to him. By contrast, they should ascribe both the perception of odor and the emotion of anger to the human Timmy.

Participants were randomly assigned to one of four scenarios. The scenarios were varied along two dimensions. In half of the scenarios the agent was a simple robot (Jimmy), while in the other half the agent was a normal human male (Timmy). Moreover, in half of the scenarios the agent successfully manipulated an object; participants were then asked whether the agent (either the robot or the human) "smelt banana” on the 7-point scale used in Study 1. In the other half the agent was prevented from successfully manipulating the object by a robot; participants were then asked whether the agent "felt anger" on the same scale. ${ }^{15}$ The two robot scenarios read as follows:

Jimmy (shown below) is a relatively simple robot built at a state university. He has a scent detector, video camera for eyes, wheels for moving about, and two grasping arms with touch sensors that he can move objects with. As part of a psychological experiment, he was put in a room that was empty except for one box of peeled bananas, one box of chocolate, and one box of peeled oranges. The boxes were closed, but had small holes to let the scent through (Jimmy couldn't see what was in the boxes). The boxes were otherwise identical. An instruction was then transmitted to Jimmy. It read: "Put the box of bananas in front of the door.” Jimmy did this with no noticeable difficulty. Did Jimmy smell banana?

Jimmy (shown below) is a relatively simple robot built at a state university. He has a video camera for eyes, wheels for moving about, and two grasping arms with touch sensors that he can move objects with. As part of a psychological experiment, he was put in a room with another simple robot; the room was otherwise empty except for one blue

\footnotetext{
${ }^{15}$ We replicated the experiment with the question "Was Timmy/Jimmy angry..." instead of the question "Did Timmy/Jimmy feel anger....” Since this variation had no effect on participants' answers, we present only their answers to the question formulated with "feel anger" to match the formulation used in study 1 for "feel pain.” For discussion of the construction "feeling + psychological predicate” see Sytsma and Machery (2009).
} 
box, one red box, and one green box (the boxes were identical in all respects except color). An instruction was then transmitted to Jimmy. It read: "Put the red box in front of the door." When Jimmy went to move the red box, the other robot ran into him, preventing him from reaching the box. Jimmy tried again and again and each time the robot banged into him. Jimmy finally rammed the other robot; when the robot moved away from him, Jimmy chased after the robot. Did Jimmy feel anger?

\subsection{Results}

Figure 4 and Table 2 summarize the results.

\begin{tabular}{c|cc}
\hline & Smelling Banana & Feeling Anger \\
\hline Human & $N=18,5.83(1.46) * * *$ & $N=25 ; 5.84(.99) * * *$ \\
Robot & $N=28 ; 3.89(2.42)$ & $N=35 ; 3.06(2.22)^{*}$ \\
\hline$* p<.05 ; * * p<.01 ; * * * p<.005$ &
\end{tabular}

\section{Table 2: Results of Study 2 (number of participants per condition, mean answer, and standard deviation in parentheses; significance tests compare means to the neutral answer, 4).}

Unsurprisingly, participants were willing to ascribe both smelling banana and feeling anger to

Timmy. By contrast, participants were reluctant to ascribe feeling anger to the robot Jimmy (their mean answer was significantly lower than 4) and were ambivalent about ascribing smelling banana (their answer was not significantly different from 4). Thus, in contrast to seeing red, people are not willing to ascribe smells to a simple robot. While most of the folk were willing to ascribe seeing red to the robot (more than $80 \%$ of participants gave a score of 4 or higher), they were more evenly split for the case of smelling banana (around 50\% gave a score of 4 or higher). 


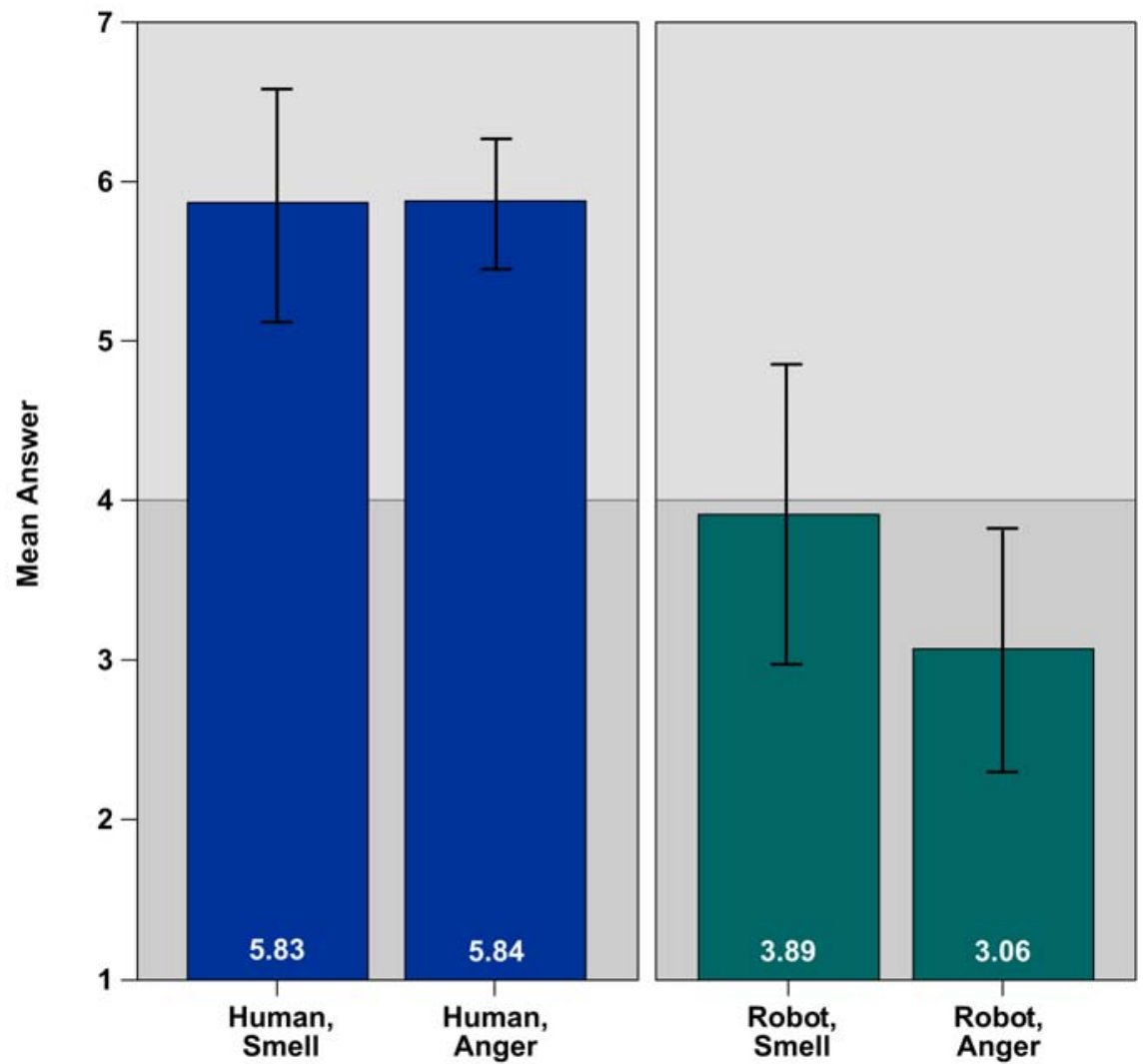

Figure 4: Study 2, Results (error bars: 95\% confidence interval).

\subsection{Discussion}

These results speak against the internal/external hypothesis as formulated: The folk do not appear to treat all external senses the same-they do not treat smelling banana analogously to seeing red. Our results suggest that the folk do not understand subjective experience in terms of a distinction between being internal and being external.

One possible response is to charge that our characterization of the division between the external and the internal is too coarse. For example, Newton $(2000,64)$ implies that not all the external senses are equally external: Where colors are seen as properties of external objects, she argues that this holds to only a lesser degree for sound. The folk might treat smell as yet more borderline between external and internal: While the sense of smell gives us information about 
external objects, the scent can seem to be located at or in the nostrils. A nuanced internal/external hypothesis would predict that the folk’s willingness to ascribe perceptual states to a simple robot varies inversely with how external the sense is.

An alternative response is also suggested by Newton (1989), as well as the discussion of Robbins and Jack (2006) in section 2-it might be that the folk conception of subjective experience is closely tied to those mental states that have a valence. Thus, Newton argues that experiences of colors and pains differ in that the latter has an "affective aspect" that the former lacks: "To have a pain is to have something that one does not like. Since not liking something is a psychological state, it has seemed as if pains, even if they are associated with our physical bodies, are also psychological in a way that e.g. colors, in this respect at least, fail to be.” (574). We hypothesize that it is not whether a mental state is the product of the external senses that matters for the folk understanding of subjective experience, but whether they associate that state with some hedonic value for the subject.

Note that there is much correspondence between the division between states with or without a valence and the internal/external division: the states explored in experiment 1 separate under each distinction; seeing a red box is both external and lacks valence, while feeling pain from an electric shock is both internal and has a valence. Nonetheless, not all external mental states lack valence; like feeling pain, but unlike seeing colors, tastes and smells are typically associated with hedonic value.

Thus, for a perceptual experience like seeing red that is neither liked nor disliked, the folk readily attribute it to the robot Jimmy. For non-perceptual mental states with clear valence like feeling pain or feeling anger, the folk readily deny them of Jimmy. For a perceptual state like smelling banana that has an associated valence, however, the folk are divided. We conjecture 
that they are divided because they hold that while Jimmy is capable of perceiving the scent of banana, he is incapable of having the valence; he is incapable of liking the scent of banana. The folk are divided, here, because unlike pain where its valence is essential to it being pain, for smell they see the valence as potentially disassociating from the perceptual aspect. In other words, there is an ambiguity in the question "did Jimmy smell banana”-not between an "informational" and a "phenomenal" reading (see section 3.5), but between a "perceptual" and a "valence" reading — that is not present for the questions about seeing red and feeling pain. This ambiguity is suggested by the wide distribution of responses (Figure 5): $42.9 \%$ of the folk gave a negative response (a score below 4) while $48.6 \%$ gave a positive response (a score above 4).

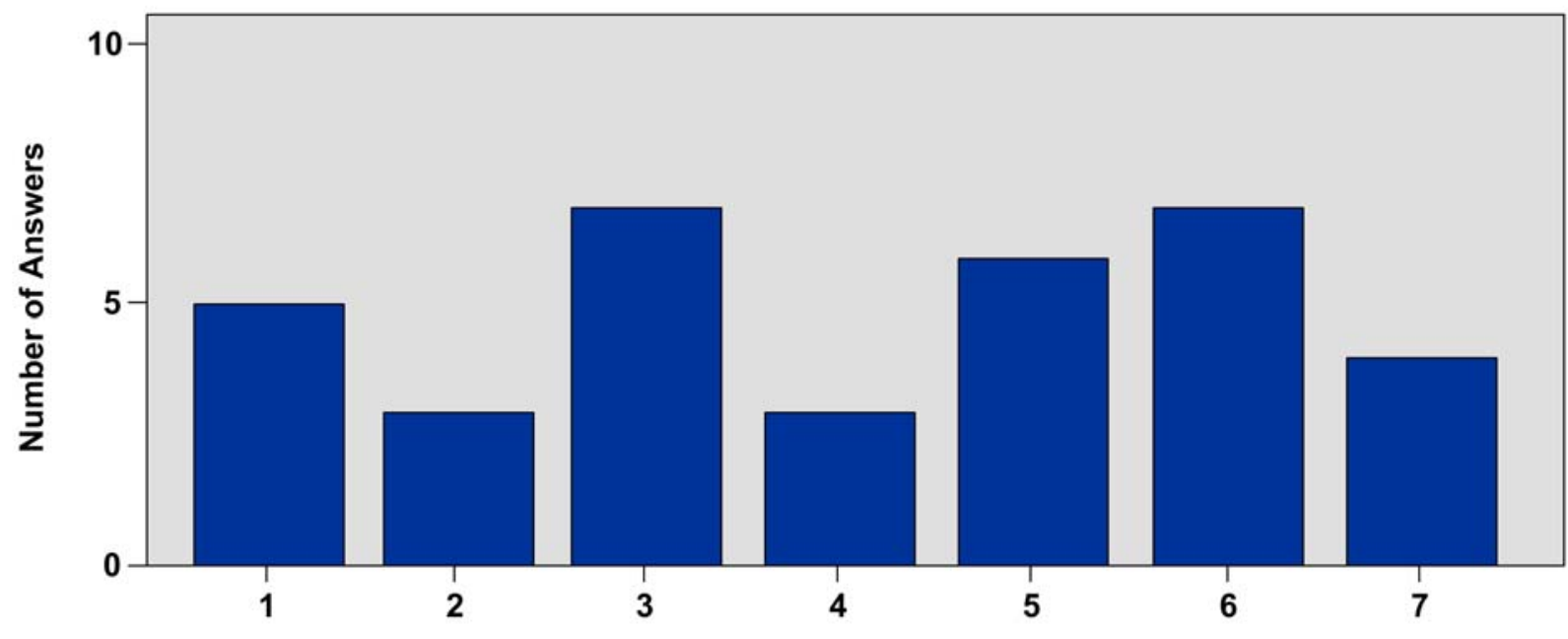

Figure 5: Distribution of the folk's answers for the question, "Did Jimmy smell banana?”

If this explanation is correct, then we would expect that downplaying the valence reading for smell will increase the folk's willingness to attribute the state to the robot Jimmy. Specifically, we predict that for a "neutral" odor (an odor that participants are unfamiliar with and thus associate no valence with), participants will be more willing to say that Jimmy smells it than familiar odors like banana. Testing this prediction is the focus of our third experiment. 


\section{Study 3: The Valence of Smell}

That the sense of smell has strong connections to emotion and emotional memory is well recognized. It is obvious that we tend to find many odors distinctly pleasant or unpleasant. In recent years, a great deal of scientific work has been conducted on the emotional processing of olfactory stimuli. This work indicates that in contrast with visual stimuli, odors more readily elicit emotional responses and more readily call forth emotional memories (see, for example, Herz et al. 2004). Most recently, neuroimagining data has provided evidence that the emotional potency of memories elicited through smell are correlated with activation of the amygdala, a brain structure that is critical for processing emotive stimuli and for emotional memory (Winston et al. 2005). It is therefore not surprising that the sense of smell would be tied to valence since unlike the other sensory systems, the olfactory system projects directly to the amygdala.

Given this, it is reasonable to expect that participants associated each of the common olfactory stimuli described in experiment 2—banana, orange, and chocolate-with a valence. These are odors that most people are familiar with and find to be pleasant. We hold that this valence explains people's relative unwillingness to say that the robot Jimmy smelled banana in comparison to saw red.

To test this we ran a further variation on the Timmy/Jimmy probes. We tested folk responses for three sets of olfactory stimuli—familiar unpleasant stimuli (e.g., vomit), familiar pleasant stimuli (e.g., banana), and unfamiliar stimuli (e.g., isoamyl acetate). We predicted that the participants' willingness to attribute smell to the robot is sensitive to whether a valence is associated with the stimulus: Participants would be more willing to say that Jimmy could smell a stimulus that they did not associate with a valence than one that they did. 
Participants were randomly assigned to one of six scenarios. The scenarios were varied along two dimensions. In half of the scenarios the agent was a simple robot (Jimmy), while in the other half the agent was a normal human male (Timmy). In each of the scenarios the agent successfully manipulated an object based on an olfactory cue. The scenarios were also varied with respect to the valence typically associated with the olfactory cue. In one third of the scenarios, the olfactory cue was unfamiliar and thus associated with no valence (isoamyl acetate); in one third, it was familiar with a positive valence (banana); in one third, it was familiar with a negative valence (vomit). Finally, participants were asked whether the agent (either the robot or the human) smelt that stimulus on the 7-point scale used in previous studies.

The first of the three robot scenarios reads as follows:

Jimmy (shown below) is a relatively simple robot built at a state university. He is equipped with a microphone, scent detector, video camera, wheels for moving about, and two grasping arms with touch sensors that he can move objects with. As part of an experiment, three chemical compounds were placed under Jimmy's scent detector. The compounds were presented one at a time. As they were presented their names were transmitted to Jimmy: Isoamyl Acetate, 3-Methylbutanal, and Dipentene. The next day Jimmy was put in a room that was empty except for one box of Isoamyl Acetate, one box of 3-Methylbutanal, and one box of Dipentene. The boxes were closed, but had small holes to let the scent through. The boxes were otherwise identical. An instruction was then transmitted to Jimmy. It read: "Put the box of Isoamyl Acetate in front of the door." Jimmy did this with no noticeable difficulty. The test was repeated on three consecutive days with the order of the boxes shuffled. Each time Jimmy performed the task with no noticeable difficulty. Did Jimmy smell Isoamyl Acetate?

The other three scenarios varied only in the olfactory stimuli used. They were (the target is in italics):

Banana, Orange, Chocolate; Vomit, Human Feces, Rotting Dog Meat;

\subsection{Results}

Figure 6 and Table 3 summarize the results. 


\begin{tabular}{c|ccc}
\hline & Isoamyl Acetate & Banana & Vomit \\
\hline Human & $N=25,5.68(1.38) * * *$ & $N=26,5.62(1.56) * * *$ & $N=25,5.48(1.76)^{* * *}$ \\
Robot & $N=32,5.31(2.13) * * *$ & $N=35,4.11(1.98)$ & $N=34,4.18(2.30)$ \\
\hline$* p<.05 ; * * p<.01 ; * * * p<.005$ & &
\end{tabular}

Table 3: Results of Study 3 (number of participants per condition, mean answer and standard deviation in parentheses; significance tests compare means to the neutral answer, 4).

Participants were willing to ascribe each smell to Timmy. They were also willing to ascribe the unfamiliar olfactory cue (isoamyl acetate) to Jimmy (the mean answer was significantly higher than 4), but not the two familiar olfactory cues (the mean answers were not significantly different from 4). Participants’ answer to the unfamiliar smell was also significantly higher than their answer to the familiar smells and the latter were not different between each other.

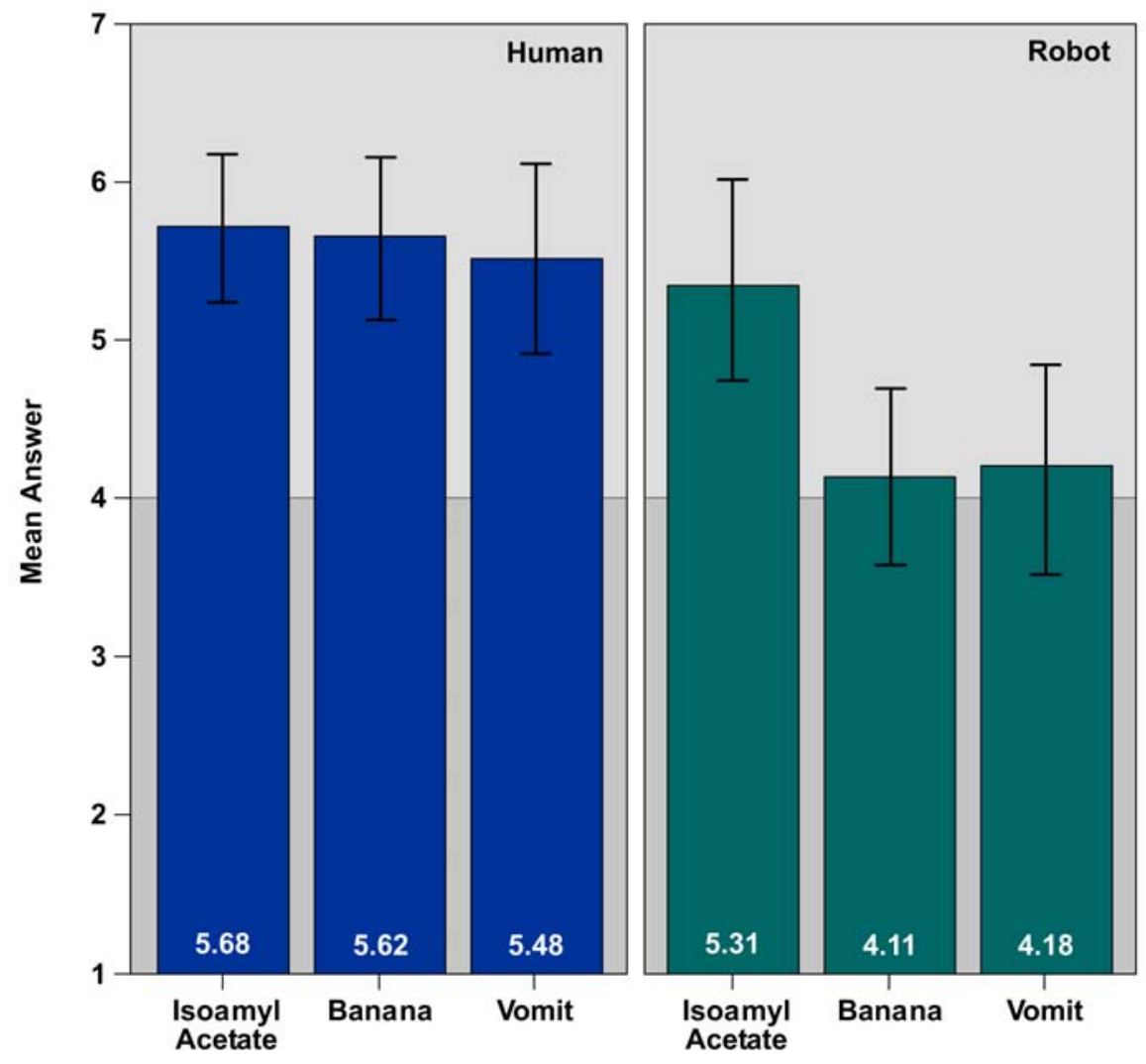

Figure 6: Study 3, Results (error bars: $95 \%$ confidence interval). 


\subsection{Discussion}

As we had predicted, people are more likely to ascribe the perception of an unknown olfactory stimulus to the robot than the perception of familiar smells associated with either positive or negative valence. The refined interior/exterior hypothesis discussed in section 4.2 can hardly account for these findings, because we found that people's disposition to ascribe a mental state to the robot varied within a single modality. Because they are olfactory states, smelling banana and smelling isoamyl acetate are equally external. Thus, the refined interior/exterior hypothesis predicts that people should treat them similarly.

By contrast, the valence hypothesis predicts people’s answers. Because people are unfamiliar with the smell of isoamyl acetate, they do not associate either a positive or a negative valence with it. Absent a specific valence, people focus on the perceptual reading of "smell” to decide whether Jimmy and Timmy can smell isoamyl acetate. By contrast, both the smell of banana and the smell of vomit are associated with valence. Because people tend to believe that only living creatures have likes and dislikes, they are relatively unwilling to ascribe these two smells to the robot. This is consistent with the proposal that the folk conceive of subjective states as states with an associated valence: People distinguish between different types of perceptual experiences, bodily sensations, and felt emotions depending on their valence.

\section{Phenomenal States and Valence}

\subsection{The Common-sense Understanding of Subjective Experience}

The experimental studies reported on above offer preliminary evidence that the folk do not recognize the phenomenality of mental states such as seeing a color, hearing a sound, smelling, feeling pain, and experiencing some emotion. To put the same point differently, in clear contrast 
to philosophers (Section 1), the folk do not seem to believe that there is something common to all these mental states—namely that they are phenomenal. The evidence for this difference between the folk and philosophers comes from three sources. First, study 1 showed that the folk are willing to ascribe seeing red to a simple robot, but deny that it feels pain; in contrast, philosophers deny that the robot can be in either state. Second, unlike philosophers, the explanations given by those folk who deny that the robot could see red did not indicate that phenomenality was at issue. Finally, studies 2 and 3 support our positive account of the folk conception of subjective experience: The folk's responses across modalities, and for a range of stimuli within the olfactory modality, correspond with the valence of those states, but not with their phenomenality.

We have seen that the folk are much more likely to ascribe mental states that lack valence (seeing red or smelling isoamyl acetate) to the robot than they are to ascribe a mental state with positive or negative valence (feeling pain, feeling anger, smelling banana, or smelling vomit). While each of these states is phenomenal, only those states that the folk were willing to ascribe to the robot Jimmy lacked a valence. Furthermore, people's relative willingness to ascribe the other mental states to the robot seems to correlate with traditional views about how essential valence is to that state. Valence is strongly associated with mental states like feeling pain or anger and the folk were unwilling to ascribe these states to Jimmy; in contrast, smelling banana and smelling vomit involve perceptual discriminations that can be carried out in the absence of any valence and participants were split in ascribing these states to Jimmy. For isoamyl acetatean olfactory stimulus with no known valence for most people—-however, participants were willing to say that Jimmy could smell it. Thus, across perceptual modalities, people's willingness to ascribe a mental state to a simple robot depends on the valence associated with the relevant 
perceptual modality and within the olfactory modality, people distinguish between mental states with and without a valence (Figure 7).

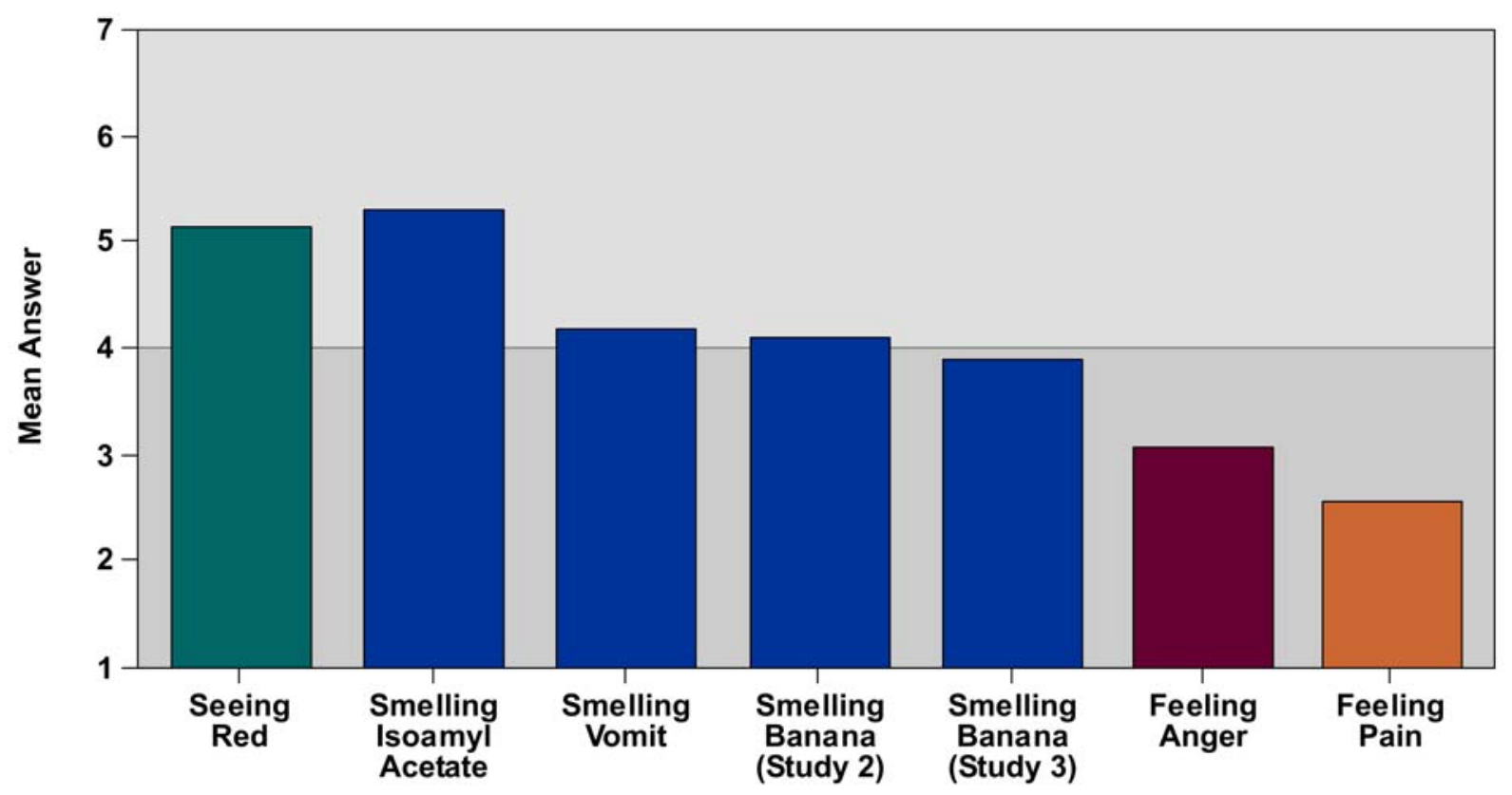

Figure 7: Folk's mean answers for mental state ascriptions to the robot Jimmy, within and across perceptual modality.

Of the accounts of the folk understanding of subjective experience considered in this article, only our account predicts this pattern of answers. If people recognized the phenomenality of mental states such as seeing red and feeling pain, they would treat them similarly. But they don't. If people conceived of subjective mental states in terms of internal states (in contrast to the states produced by our external senses), they would treat similarly smelling banana and seeing red on the one hand and smelling isoamyl acetate and smelling banana on the other. But they don't. 


\subsection{Philosophical Implications}

What we have offered in this article in an initial empirical account of the common-sense conception of subjective experience. We have also presented preliminary evidence that it differs significantly from the philosophical concept of phenomenal consciousness. In contrast to philosophers' emphasis on the phenomenality of subjective mental states, for the folk, subjective states seem to be primarily states with a valence. We are aware that much work remains to be done to establish our hypothesis about the folk conception of subjective experience. ${ }^{16}$ For the sake of the argument, however, we will assume in the remainder of the paper that it is by and large correct. We believe that the preliminary evidence reported here at least justifies taking seriously the hypothesis that philosophers' and ordinary people's conceptions of subjective experience differ in the way we proposed.

Understanding the common-sense conception of subjective experience is fascinating in its own right. It is also philosophically important. Although further research is needed to confirm the valence hypothesis, if correct it has some significant philosophical implications. First, some philosophers have claimed that philosophers and ordinary people conceive of subjective experience in basically the same way. Block (2004) likens the philosophical conception of subjective experience to the common-sense conception of subjective experience. Similarly, Dennett holds that the concept of phenomenal consciousness is part of "the lore" of our folk theory of consciousness that we pick up "in the course of our enculturation” (2005, 26-27), Patricia Churchland talks of "the old folk notion of consciousness" (1988, 302), and Alvin Goldman writes about “the folk-psychological notion of phenomenal consciousness” (1993,

\footnotetext{
${ }^{16}$ Particularly, one might argue that the fact that ordinary people have no difficulty understanding the classical thought experiments about consciousness, such as the inverted spectrum thought experiment, shows that the folk conception of subjective experience coincides with the concept of phenomenal consciousness. We are currently examining whether people really grasp these thought experiments.
} 
364). In line with such claims, we found in study 1 that philosophers believe that ordinary people will give approximately the same answers as themselves. Our findings belie such claims.

Second, and more important, if further research supports our finding that there is a difference between the philosophical concept of phenomenal consciousness and the folk conception of subjective experience, it will have some significant implications for some central debates in philosophy of mind. We have particularly in mind Chalmers's hard problem of consciousness or Levine’s explanatory gap.

For the sake of space, we focus on Chalmers's articulation of the problem. In substance, this problem is the following: supposing that one were able to describe all the functional properties of a mental state such as seeing red or feeling pain, something would remain unexplained, namely the phenomenal aspect of red (the redness of red) and the phenomenal aspect of pain (the painfulness of pain). Chalmers puts this problem as follows (1995, 203):

[E]ven when we have explained the performance of all the cognitive and behavioral functions in the vicinity of experience-perceptual discrimination, categorization, internal access, verbal report - there may still remain a further unanswered question: Why is the performance of these functions accompanied by experience?

The sense of "experience" at issue is the philosophical conception of subjective experience, which unites perceptual experiences, bodily sensations, and felt emotions as each having a phenomenal aspect (see Chalmers's quotation in Section 1).

At this juncture, it is important to ask why we should believe that there is really a hard problem of consciousness. That is, why should we believe that there are experiences, as defined, such that an aspect of them is expected to be left unexplained even after we have thoroughly accounted for their functional roles? Chalmers's answer is characteristically limpid. As noted above, he suggests that phenomenal consciousness is undeniable because it is "the most central and manifest aspect of our mental lives” $(1995,207)$. In other words, on the basis of their 
introspective, first-person access to mental states such as seeing red or feeling pain, we are supposed to know that these mental states have phenomenal properties. As such, phenomenal consciousness has the status of an explanandum, but explaining it poses a hard problem: Chalmers holds that when we compare our first-person knowledge of the phenomenal properties of states such as feeling pain and seeing red to the functional accounts of these mental states, we will conclude that these accounts have failed to explain what had to be explained—viz. what it is like to be in pain and to see red.

Our findings cast some doubt on Chalmers's and others' justification of the hard problem of consciousness. If the account of the folk conception of subjective experience presented in this article is correct, then the folk do not find phenomenal experience manifest; their first-person experience with mental states such as seeing red and feeling pain does not lead them to judge that these mental states are united by each having a phenomenal aspect. But if most people do not judge that mental states such as feeling pain or seeing red have phenomenal properties in spite of their introspective experience with these states, then phenomenal consciousness can hardly be supposed to be "the most familiar and manifest aspect of our mental lives," as Chalmers puts it. It would be unclear whether these mental states have phenomenal properties at all. But, then, why should we view the hard problem of consciousness as a genuine problem?

It is worth contrasting the argument made here with the argument developed by Robbins and Jack (2006). Like us, Robbins and Jack link the common-sense conception of subjective experience to valence. They further argue that this common-sense conception is the source of the philosophical concept of phenomenal consciousness and of the resulting hard problem of consciousness. They conclude that while this problem is a pseudo-problem, "the gap intuition is psychologically real and deep” (60). By contrast, we have argued that philosophers and ordinary 
people conceive of subjective experience differently. If this is correct, then the folk conception of subjective experience is not the origin of the hard problem of consciousness and cannot be used to underwrite it. Our skeptical challenge concludes that this undermines the usual justification for this supposed problem.

At this point, Chalmers and others might attempt to meet this skeptical challenge in two different ways. (Remember that for the sake of the argument, we are taking for granted that philosophers and ordinary people conceive of subjective experience differently). First, they might argue that the fact that ordinary people do not conceive of subjective experience as being phenomenal does not undermine the claim that subjective experience is phenomenal. Second, they might reformulate the hard problem of consciousness by focusing on the valence of pain and anger rather than on their phenomenality. We consider these two replies in turn, starting with the latter.

Our results suggest that the folk do not treat the diverse states at issue as being united by having phenomenal properties; rather they distinguish between them on the basis of valence. On this basis, we have asked, in a skeptical manner, why we should believe that there is a hard problem of consciousness. It is natural to reply that the valence of pain and anger raises a problem that is similar to the hard problem of consciousness: even if we knew all the functional and neural properties of pain and anger, one would not have explained why they have a valence.

This reply should be resisted. The hard problem specifically concerns phenomenal properties: It is the phenomenal properties that are thought to resist functional explanation. Valence, on the other hand, does not seem to raise this issue. It is far from clear why one would expect states with a valence to resist functional or neuronal explanation: the hedonic value of a stimulus or a bodily state seems to be an evaluation of its expected value to the organism. It 
might, of course, be conjectured that the folk understand the valence of states like feeling pain in such a way that they resist functional or neuronal explanation. Additional empirical work is needed to articulate how the folk actually understand the valence of states like pain, but in advance of such work we see little reason to expect that they understand valence in a way that would raise a problem that is similar to the hard problem of consciousness. Furthermore, even if it were to turn out that the folk understand valence in such a way, it is unclear that the resulting problem would have the philosophical force that the hard problem of consciousness has been thought to have, as opposed to being more akin to the problem raised by people holding a vitalist conception of life: Regardless of whether or not people hold that valence resists explanation, it is not clear why we should think that it actually does so.

Let's turn now to the other reply to our skeptical challenge. Chalmers and others might reply that justifying the hard problem of consciousness does not require that most people actually judge that mental states such as seeing red or feeling pain have phenomenal properties. It only requires that people who have carefully considered what it is like to be in such mental states make this judgment. Chalmers might then add that as our quotations illustrate, most philosophers have indeed done so.

It is currently unknown whether most people who have carefully considered what it is like to see red or feel pain do make this judgment. Artists, physicians, practitioners of various meditation practices, and so on, have presumably given due attention to such experiences, but we doubt that this introspection makes the philosophical concept of phenomenal consciousness any more obvious. Rather, we suspect that the proposition that subjective experience is phenomenal only becomes obvious as one is trained into a particular way of thinking about the mind. ${ }^{17}$

\footnotetext{
${ }^{17}$ While most philosophers seem to find phenomenal consciousness obvious, we suspect that this has not been the case for scientists. In fact, philosophers have often criticized psychologists and neuropsychologists for failing to see
} 
Now, if phenomenal consciousness only comes to seem obvious with philosophical training, then it is unclear whether the hard problem should be seen as raising a genuine challenge for philosophers, psychologists, and neuroscientists, as opposed to pointing out that there is a problem with the philosophical concept of phenomenal consciousness. The hard problem seems particularly cogent, because it is alleged that it is pretheoretically obvious that mental states like seeing red and feeling pain are phenomenal. Because this judgment is pretheoretical, it is difficult to challenge it on the ground that it is informed by one's philosophical perspective on consciousness. By contrast, if the judgment is not pretheoretical but is informed by one's philosophical perspective, then the hard problem can be rephrased as an argument against taking the theoretical concept of phenomenal consciousness to pick out an actual explanandum.

As an alternative reply to our argument, proponents of the hard problem of consciousness might argue that even though most people do not actually conceive of subjective experience as being phenomenal, they can easily be taught to conceive of them as phenomenal. It is important that this be easy if the hard problem is to remain cogent. Thus, the response concedes that while the folk do no spontaneously recognize phenomenal experience, it is nonetheless pretheoretical. Consider the analogy of pointing out to someone that their missing keys are in plain view. Like the keys, the proponent of the hard problem might argue that phenomenal experience is obvious, but that until it is pointed out to them many people miss it. To support this claim, they could appeal to their own experience of teaching undergraduates Nagel's notion of what it is like to have a conscious mental state or Levine’s explanatory gap.

that their account of consciousness failed to solve the hard problem (see Chalmers 1995, section IV, for example). We suspect that many psychologists and neuropsychologists have not failed in this respect by accident. Rather, it might be that like the folk, they do not conceive of subjective experience as being phenomenal, in spite of having plausibly carefully considered "what it is like" for them to see red, feel pain, and so on. For this reason, they might not recognize that there is a further aspect of these mental states that needs explaining. 
We are not convinced, however. We concede that if people could easily be taught to recognize the phenomenality of mental states such as seeing red and feeling pain, then the worry we have been raising would be alleviated. However, it is unclear whether the antecedent of this conditional is true. In our experience, many ordinary people either don't understand or don’t take seriously the philosophical concept of phenomenal consciousness even after a lengthy explanation. It does not seem to us that the keys are in plain view.

\section{Conclusion}

We have provided some preliminary evidence that philosophers and ordinary people conceive of subjective experience in markedly different ways. Philosophers propose that subjectively experienced mental states have phenomenal properties: There is something it is like to see red, smell banana, feel anger, and be in pain. By contrast, ordinary people do not recognize that there is something common to all these states—viz. that they are phenomenal. Rather, they distinguish between the states that have a valence, such as pain, anger, and smelling banana, and the states that do not, such as seeing red and smelling isoamyl acetate. We have also argued that these empirical findings cast some doubts on whether there is really a hard problem of consciousness. The hard problem is typically justified on the grounds that we are acquainted with the phenomenal properties of states such as pain and seeing red and that functional accounts of mental states fail to explain how they can have such phenomenal properties. Our findings challenge the first premise of this argument. Because people do not seem to conceptualize their subjective mental life as phenomenal, it is at least unclear that we are pretheoretically acquainted with the phenomenal properties of our conscious mental states. 


\section{Appendix}

\section{Study 1: Seeing Red and Feeling Pain}

671 participants completed surveys through the Mental State Intuitions Study website. 68 participants were excluded because their biographical information was incomplete or because their comments indicated they misunderstood the probe. Biographical information was considered "incomplete" if we could not sort the participant into either the philosopher or the non-philosopher groups (see footnote 8). Participants were judged to misunderstand the probe mostly for the following reasons: they stated that the electric shock was not painful, they understood "see red" as meaning "is angry," or they stated that the robot was under remote control. Of the remainder, $61 \%$ were male; the mean age was around 33 (range: 18-68). There were 372 philosophers (71\% male; mean age around 33) and 231 non-philosophers (46\% male; mean age around 31).

A three-way ANOVA with type of agent, type of mental state, and philosophical training as between-participant factors yielded a main effect of the type of agent (Timmy > Jimmy), a main effect of the type of mental state (seeing red > pain), a main effect of philosophical training (non-philosophers > philosophers) and three two-way interaction (type of mental state by type of agent; type of mental state by philosophical training; type of agent by philosophical training). Planned analyses showed that philosophers' mean answers for both feeling pain and seeing red were significantly above 4 for Timmy (red: $N=92, M=5.90, S D=1.46, p<.005$; pain: $N=84$, $M=6.44, S D=.87, p<.005$ ) and significantly below 4 for Jimmy (red: $N=96, M=3.48, S D=1.94$, $p<.01$; pain: $N=100, M=2.02, S D=1.53, p<.005)$; non-philosophers treated the states dissimilarly, the mean answers for Timmy being significantly above 4 (red: $N=55, M=5.98, S D=1.25, p<.005$; 
pain: $N=62, M=6.15, S D=1.01, p<.005)$, as was the mean answer for Jimmy seeing red $(N=52$, $M=5.15, S D=1.85, p<.005$ ), while the mean answer for Jimmy feeling pain was significantly below $4(N=59, M=2.54, S D=1.99, p<.005)$. The difference between the average folk ascription of seeing red and of feeling pain is statistically significant $(t(109)=7.12, p<.001)$ and the effect size $(d=0.87)$ is large (Cohen 1992).

\section{Study 2: Smelling Banana and Feeling Anger}

253 participants completed surveys through the Mental State Intuitions Study website. 31

participants were excluded because their biographical information was incomplete, because they had indicated they had already participated to the Mental State Intuitions Study, or because they were not 18 year old. Since this study was aimed at exploring the pattern of folk responses seen in our first experiment, an additional 63 participants were excluded based on their responses to biographical questions concerning their philosophical training (see footnote 8). Of the remainder, 38\% were male; the mean age was around 30 (range: 18-75).

A two-way ANOVA with type of agent and type of mental state as between-participant factors yielded a main effect of the type of agent (Timmy $>$ Jimmy; $F(1,102)=36.84, p<.001$ ) and no other main effect or interaction. Planned analyses showed that the mean answers for both smelling banana and feeling anger were significantly higher than 4 for Timmy (banana: $N=18$, $M=5.83, S D=1.46, p<.005$; anger: $N=25, M=5.84, S D=0.99, p<.005)$; the mean answer was significantly below 4 for Jimmy feeling anger $(N=35, M=3.06, S D=2.22, p<.05)$ and neutral for Jimmy smelling banana $(N=28, M=3.89, S D=2.42)$. 
Study 3: The Valence of Smell

211 participants completed our survey in a classroom setting. 34 participants were excluded because their biographical information was incomplete, because they were philosophers (see footnote 8), because they had already completed one of our surveys, or because they were not 18 years old. Of the remainder, 33.5\% were male; the mean age was around 20 (range: 18-30).

A two-way ANOVA with type of agent and type of olfactory cue as between-participant factors yielded a main effect of the type of agent (Timmy > Jimmy; $F(1,171)=13.17, p<.001$ ) and no other main effect or interaction. Planned analyses showed that participants' mean answers for each of the three target smells for Timmy were significantly above 4 (isoamyl acetate: $N=25$, $M=5.68, S D=1.38, p<.005$; banana: $N=26, M=5.62, S D=1.56, p<.005$; vomit: $N=25, M=5.48$, $S D=1.76, p<.005$ ); the mean for the unfamiliar smell (isoamyl acetate) for Jimmy was also significantly above 4 ( $N=32, M=5.31, S D=2.13, p<.005$ ), but the scores were neutral for the two familiar smells for Jimmy (banana: $N=35, M=4.11, S D=1.98$; vomit: $N=34, M=4.148, S D=2.30$ ). Participants mean answer to the unfamiliar smell was significantly higher than either familiar smell (banana: $t(65)=-2.28, p=.02$; vomit: $t(65)=-2.08, p=.04$ ), while for the unfamiliar smells the mean answers were not different between each other $(t(67)=-.12, p=.9)$. 


\section{References}

Arico, A. (forthcoming). Folk psychology, consciousness, and context effects. Review of Philosophy and Psychology.

Bennett, M., \& Hacker, P. (2003). Philosophical foundations of neuroscience. Oxford: Blackwell.

Block, N. (1995). On a confusion about a function of consciousness. Behavioral and Brain Sciences, 18, 227-247.

Block, N. (2004). Qualia. In R. Gregory (Ed.), Oxford Companion to the Mind, Second Edition (pp. 785-789). New York: Oxford University Press.

Bloom, P. (2004). Descartes’ baby: How the science of child development explains what makes us human. London: William Heinemann.

Chalmers, D. (1995). Facing up to the problem of consciousness. Journal of Consciousness Studies, 2(3), 200-19.

Churchland, P. S. (1988). Reduction and the neurobiological basis of consciousness. In A. J. Marcel \& E. Bisiach (Eds.), Consciousness in contemporary science (pp. 273-304). Oxford: Oxford University Press.

Cohen, J. (1992). A power primer. Psychological Bulletin, 112, 155-159.

Crick, F. (1995). The astonishing hypothesis: The scientific search for the soul. New York: Simon \& Schuster.

Dennett, D. (1987). The intentional stance. Cambridge: MIT Press.

Dennett, D. (1996). Kinds of minds: Toward an understanding of consciousness. Cambridge: MIT Press.

Dennett, D. (2005). Sweet dreams: Philosophical obstacles to a science of consciousness. New York: Basic Books.

Goldman, A. (1993). Consciousness, folk psychology, and cognitive science. Consciousness and Cognition, 2, 364-382.

Gray, H., Gray, K., \& Wegner, D. (2007). Dimensions of mind perception. Science, 619, 315.

Herz, R., Eliassen, J., Beland, S., \& Souza, T. (2004). Neuroimaging evidence for the emotional potency of odor-evoked memory. Neuropsychologia, 42, 371-378. 
Huebner, B. (forthcoming). Commonsense concepts of phenomenal consciousness: Does anyone care about functional zombies? Phenomenology and the Cognitive Sciences.

Huebner, B., Bruno, M., \& Sarkissian, H. (forthcoming). What does the nation of China think about phenomenal states? Review of Philosophy and Psychology.

Knobe, J., \& Prinz, J. (2008). Intuitions about consciousness: Experimental studies. Phenomenology and the Cognitive Sciences, 7, 67-85.

Levin, J. (1998). Qualia. In E. Craig (Ed.), Routledge Encyclopedia of Philosophy. London: Routledge. http://www.rep.routledge.com/article/V029. Accessed 4 July 2007.

Nagel, T. (1974). What is it like to be a bat? The Philosophical Review, 83(4), 435-450.

Newton, N. (1989). On viewing pain as a secondary quality. Noûs, 23(5), 569-598.

Newton, N. (2000). Humphrey’s solution. Journal of Consciousness Studies, 7(4), 62-66.

Papineau, D. (2002). Thinking about consciousness. Oxford: Oxford University Press.

Piaget, J. (1929). The child’s conception of the world. New York: Harcourt.

Prinz, J. (2006). Gut Reactions: A perceptual theory of emotions. New York: Oxford University Press.

Robbins, P., \& Jack, A. (2006). The phenomenal stance. Philosophical Studies, 127, 59-85.

Searle, J. (1994). The rediscovery of the mind. Cambridge: MIT Press.

Sytsma, J., \& Machery, E. (2009). How to study folk intuitions about phenomenal consciousness. Philosophical Psychology, 22(1), 21-35.

Tye, M. (2003). Qualia. In E. N. Zalta (Ed.), The Stanford Encyclopedia of Philosophy. http://plato.stanford.edu/entries/qualia. Accessed 4 July 2007.

Wellman, H. M., \& Estes, D. (1986). Early understanding of mental entities: A reexamination of childhood realism. Child Development, 57, 910-923.

Winston, J., Gottgried, J., Kilner, J., \& Dolan, R. (2005). Integrated neural representations of odor intensity and affective valence in human amygdala. The Journal of Neuroscience, 25(39), 8903-8907. 